\title{
DE CHARLAS DE CAFÉ A UNA POLITICA CULTURAL
}

\author{
Laura Belén Navallo ${ }^{1}$
}

Muchas veces invadidos por suposiciones e ingenuidades de índoles diversas creemos que determinadas políticas son producidas en un lugar específico y que son implantadas, en el mejor de los casos, por un decreto o ley. En esa creencia imaginamos que las políticas se realizan por un acto de magia. Esa ingenuidad puede ser equiparada a la del artista creador que por su genialidad es capaz de hacer algo diferente y por qué no estar a la vanguardia. Felizmente el trabajo etnográfico ayuda a desmitificar y ver cómo opera el mundo social, sobre qué prácticas, discursos, representaciones las relaciones sociales se construyen, en qué condiciones se llevan a cabo y qué producen esas relaciones.

En algún momento me prepuse reflexionar sobre políticas culturales en la ciudad de Salta -República Argentina- y cuando lo tuve presente algunas acciones emprendidas por el Estado provincial me resultaban evidentes, entre ellas la creación de la Orquesta Sinfónica de Salta fundada en el año 2001. ${ }^{2}$ Noté que no era una acción aislada sino que formaba parte de un conjunto de medidas vinculadas a la promoción cultural, el patrimonio y el turismo. Cada acontecimiento cultural era celebrado ya sea en el Abril Cultural Salteño o en el 17 de junio, día de la muerte de Martín Miguel de Güemes (prócer salteño que luchó contra los españoles en la guerra por la independencia). Claramente ambas fechas marcan el calendario cívico provincial aunque también a éste se incorpora el festejo de los patronos de Salta, el Señor y la Virgen del Milagro en el mes de setiembre.

Por ser salteña me resultaba prácticamente obvio que el concierto inaugural de la Orquesta Sinfónica de Salta se hubiera celebrado como cierre del Abril Cultural Salteño y que este mes cultural sea realizado por Pro Cultura Salta. Esa inauguración permitió algunas sorpresas, por una parte el mes cultural era organizado por Pro Cultura Salta y por el gobierno provincial y éste último creaba a la mencionada orquesta. Revisando folletos y

\footnotetext{
${ }^{1}$ Universidade Federal do Rio de Janeiro, Brasil.

${ }^{2}$ El análisis de los procesos sociales de creación de la orquesta sinfónica fue desarrollada en mi tesis de licenciatura denominada "Tocando cultura. Políticas y poéticas del término cultura a partir de un análisis de los procesos sociales de creación de la Orquesta Sinfónica de Salta”, defendida en la Universidad Nacional de Salta, 2007.
} 
diversas fuentes documentales de cualquier manifestación cultural ésta generalmente estaba auspiciada, apoyada o bien organizada por Pro Cultura Salta. Teniendo conocimiento que Pro Cultura es una asociación civil sin fines de lucro, muchas veces sus funciones parecen fusionarse a las del gobierno provincial. Ante esa situación comienzo a indagar sobre la formación de esta asociación civil y el proyecto sobre el que se funda, el Abril Cultural Salteño.

El objetivo de este trabajo es mostrar cómo se constituyó la entidad civil prestando atención a las prácticas y las relaciones sociales que la tornaron posible. Pro Cultura Salta fue creada para promover el arte y la cultura a través de la realización de un mes de actividades culturales. Para las personas que la idearon la formación tanto de la asociación como del Abril Cultural es presentada como una "ocurrencia" y no necesariamente como una política cultural.

Primeramente describo cómo unos amigos que se reunían periódicamente forman una entidad civil que tuvo un propósito específico, la promoción de la cultura en la provincia de Salta. La narración acerca de su surgimiento busca localizar cada una de las personas que participó del proceso mapeando las redes de las cuales cada sujeto formaba parte. Luego, por medio de ese análisis, reflexiono sobre qué significa hacer políticas culturales.

Para describir la "ocurrencia" de unos hombres he creado un relato que cuente su origen, basado en diferentes narraciones obtenidas mediante entrevistas, documentación producida por la asociación civil Pro Cultura Salta o bien por otras fuentes que refieren al asunto, procurando mantener el encanto que tuvo para las personas involucradas, fascinación que se reitera cada vez que se narra su surgimiento. ${ }^{3}$ Ese encanto habla del mito de origen del Abril Cultural Salteño. Seguidamente a ese relato mítico, analizaré los aspectos de Pro Cultura Salta como institución, la asamblea que la constituyó, los individuos que estuvieron presentes y referiré a algunos puntos del estatuto social creados en esa ocasión.

\footnotetext{
${ }^{3}$ Estos relatos se construyen a partir de las entrevistas realizadas a: Raquel González de Peñalva, Luciano Tanto y José Mario Carrer. Oportunamente situaré a cada una de las personas.

También trabajamos sobre las narraciones producidas en: "Programa de actividad de XXIII Abril Cultural Salteño. "Homenaje a los fundadores". Año 1999; los libros "Pro Cultura Salta. XXX Abriles Culturales Salteños". 2006, producido por la institución y "Con los pies en el escenario. Trayectoria del Grupo Arte Dramático y su director Salo Lisé”, 2003, de Gloria Lisé.
} 
Esa descripción busca dar cuenta de las relaciones sociales sobre las que se asienta Pro Cultura, pues se trata de grupos de amigos que, por los lazos establecidos entre sí, consiguen activar diversas redes y concretizar los Abriles Culturales. Esas relaciones, por el carácter de proximidad que las sustentan, apagan los vínculos que mantienen con el Estado. Ese efecto de distanciamiento se produce por el uso de un lenguaje cargado de desinterés, alejado de cualquier propósito político. El arte es promovido porque unos hombres "aman" la cultura y "sienten" lo que Salta necesita. De esta manera, la asociación construye un modo de experimentar lo "salteño".

Pro Cultura, como su nombre lo indica, pretende incentivarla. Si bien su mito de origen coloca a los señores como pioneros, no surgen de la nada ni de un día para el otro, sino que existía un conjunto de actividades culturales anteriores a la formación de la institución y muchos de los promotores del Abril Cultural participaban y colaboraban en ellas.

Todas estas indagaciones me conducen a preguntarme cómo se producen formas de legitimación de valores sociales en torno a un objeto, en este caso llamado cultura y entendida ésta como arte. Esto ayuda a debatir las relaciones sociales que se generan mediante la cultura, los organismos que intervienen en su gestión. ¿Cómo se hace política y esa clase de política en torno a un objeto llamado cultura?

\section{Charlas de café}

En 1976, en frente de la plaza principal de la ciudad de Salta, llamada 9 de julio, se encontraba una oficina de redacción del diario El Tribuno, contigua al hotel Plaza. Las personas que redactaban para la columna matutino llegaban a ese lugar a mitad de la mañana, sin necesariamente tener que cumplir un horario de ingreso a su trabajo porque su jornada laboral se extendía por las noches. A media mañana algunos amigos tomaban su tradicional café, charlaban sobre diversos temas y en esas conversaciones surgieron ideas que, en un principio, para ellos mismos resultaban descabelladas.

Entre los hombres que se acercaba a tomar un café estuvo Ricardo Castro, un apasionado por el cine y el teatro. Viajaba cada tanto a la "Primavera Cultural" que se realizaba durante el mes de setiembre en la ciudad vecina de San Miguel de Tucumán. Uno de sus amigos señala que su trabajo de vendedor de máquinas de panadería le permitía 
viajar por distintos lugares del país y de esa forma participar tanto de eventos artísticos culturales como así también establecer vínculos con distintas personas. Sin embargo fue su pasión por el cine lo que lo puso en movimiento. En 1971 crea el Cine Arte (un ciclo de proyecciones de películas no comerciales o que regularmente no pasaban los cines comerciales) y partir de esa fecha, además del cine, periódicamente llevaba a Salta espectáculos unipersonales o pequeños grupos de teatro procedentes de la ciudad de Buenos Aires.

Entre esos hombres estuvo Luciano Tanto ${ }^{4}$, periodista del diario El Tribuno. Según él, ambos se juntaban cada mañana a tomar un café y a conversar. Luciano y Ricardo comenzaron a establecer su amistad a partir de una labor conjunta en la redacción de una revista sobre cine, editada por la Universidad Nacional de Tucumán (cuando en Salta aún existía una filial de ella antes de tornarse Universidad Nacional de Salta en 1975). Existían otras personas en ese proyecto. Cada vez que Ricardo volvía de Tucumán contaba historias sobre el movimiento allí generado gracias a las actividades artísticas presentadas. Pues por aquel entonces Tucumán era "la Paris de Salta", según apunta Luciano. Estos dos señores comenzaron a madurar la idea de hacer algo similar en Salta, ¡por qué no! Y en esas conversaciones, de tanto en tanto, se unía Ramiro Peñalva, jefe de redacción del diario mencionado. Ramiro, además de su actividad de periodista era escritor. ${ }^{5}$ Años anteriores, entre 1968-1970 estuvo en el cargo de Secretario de Estado de Prensa en los gobiernos provinciales del Ingeniero Hugo Alberto Rovaletti y Carlos Ponce Martinez, mientras que en la presidencia se encontraba el general Juan Carlos Onganía, un gobierno conquistado por un golpe de Estado. Estos hombres, unidos por el interés de crear una movida cultural en Salta, charlaron y tomaron más de un café...

A esos debates se fueron sumando otras personas, como por ejemplo Benito Crivelli. ${ }^{6}$ Italiano de nacimiento, emigrado a la Argentina con diecisiete años aproximadamente. Arribó a Salta luego de la venida de un hermano mayor. Consiguieron instalarse en la ciudad por la encomienda de unos sacerdotes salesianos para el manejo de una imprenta. Con el tiempo Benito sería contratado por el diario El Intransigente para

\footnotetext{
${ }^{4}$ Nacido el 11/4/1942. Fue corresponsal del diario El Tribuno en Italia durante 1980-1989. Trabajo al que se refiere como exilio durante la última dictadura militar en Argentina (1976-1983).

${ }^{5}$ Programa de actividad de XXIII Abril Cultural Salteño. “Homenaje a los fundadores”. Año 1999.

${ }^{6}$ Nació el 15/7/1925 en Bérgama, Italia. Murió en Salta el 25/8/1998.
} 
encargarse de la imprenta. En Salta consiguió ser dueño de la librería El Colegio, lugar que funcionó como un espacio de realización de diversas actividades culturales: presentaciones de libros, escenificación de obras de teatro (el "mini teatro" de la librería El Colegio), conciertos de música de vez en cuando. Allí se realizaron los encuentros de la Asociación Amigos de la Música, de la cual Benito era su presidente. Benito también se uniría al proyecto de los muchachos, pues compartía esos intereses y gustos. ${ }^{7}$

Ricardo llamó a un amigo para que se incorpore, Esdras Gianella, un artista local, vinculado a la escultura, quien a su vez era secretario del Club de Leones de Salta. En dicho Club se realizó también el cine arte, donde Ricardo proyectaba películas.

En esos cafés participaron eventualmente mujeres, como por ejemplo Raquel González de Peñalva, esposa de Ramiro. Maestra de sexto grado de un colegio católico renombrado de la localidad, el Belgrano. En raras ocasiones concurrió a los cafés Zenaide Lisi, pianista de fuerte actividad pedagógica en la ciudad, además de destacarse por su virtuosismo. Esposa de Benito Crivelli, “ella no frecuentaba tanto estas reuniones por la dedicación a su profesión”, dijo Raquel.

En las conversaciones de café comenzó a discutirse qué mes sería el más apropiado para llevar adelante este proyecto y cómo hacerlo... Entonces fue Ramiro quien propuso “institucionalizar un poco más la cosa”, apuntó Raquel. De esa manera conseguirían apoyo, subsidios, unir ideas y recursos de distintos tipos. Se decidió hacer, al igual que en Tucumán, un mes de actividades artísticas, Ricardo interesado por el teatro quería que sea un mes teatral, "no sé si convendrá", comentaron los otros, "por qué no mejor un mes cultural, algo que sea ecléctico", dijo Luciano. "Sí, que haya música, pintura, teatro, todas las artes", continuaron argumentando.

Pero ¿qué mes sería el más adecuado?, comenzaron a preguntarse:

- setiembre no porque es la fiesta del Señor y la Virgen del Milagro,

- octubre tampoco, está muy encima,

- la gente está como en otra cosa, es fin de año,

- El inicio del año tampoco. En marzo todos están ocupados con las clases y el ciclo lectivo,

- tal vez lo mejor sea abril

- sí, los cerros están verdes todavía, se pueden hacer cosas al aire libre

- claro, además es el mes de la fundación de Salta

- el clima sigue siendo agradable, no hace tanto frío todavía

\footnotetext{
${ }^{7}$ Algunas de las referencias en torno a la vida del señor Crivelli y de su apoyo en distintas actividades artísticas se extrajeron del libro de Gloria Lisé denominado "Con los pies en el escenario. Trayectoria del Grupo Arte Dramático y su director Salo Lisé”, 2003.
} 
Al reflexionar sobre la puesta en marcha de esta "aventura cultural" se dieron cuenta que "para que la cosa tenga más presencia" era bueno institucionalizar, crear una organización que les permita accionar desde distintos lugares contando con diferentes tipos de respaldos. Fue en ese momento cuando Luciano tomó una decisión, no le interesaba formar parte de ninguna institución, aunque se proponía continuar trabajando. De esa manera habló con Roberto Romero, dueño del diario El Tribuno. Este hombre se dispuso a colaborar en todo lo que necesitaran dándoles un espacio en la sección de "Sociedad, Cultura y Espectáculos".

Esta idea se tornó el Abril Cultural Salteño, ganaron primero un espacio en esa sección del diario y luego, viendo la presencia que estaba adquiriendo, Roberto les cedió todo una página para el evento, llamándose ésta Abril Cultural Salteño.

\section{Pro Cultura Salta: la asamblea}

Pro Cultura Salta es una asociación civil sin fines de lucro creada en diciembre 1976. Su formación se produjo en una asamblea que tuvo lugar en la antigua Casa de la Cultura, hoy completamente remodelada, un día 17 de diciembre de 1976. En el local donde se realizó la convocatoria funcionó la Dirección General de Cultura de la Provincia y también LV9 Radio Salta. Como muchas instituciones, su puesta en marcha y la realización efectiva de sus actividades se inicia en un determinado momento y después de algunos años se oficializa su funcionamiento. Con esto quiero decir que ésta, como un caso entre varios, comienza a actuar a partir de diciembre de 1976, apareciendo su acta fundacional recién en noviembre de 1979.

El estatuto sobre el que se asienta y da origen a dicha asociación fue aprobado por el Ministerio de Gobierno, Justicia y Educación de la Provincia mediante Resolución $\mathrm{N}^{\circ} 558$ D. Se reconoce su Personería Jurídica el 9 de junio de 1980. Ese estatuto tuvo una modificación en 1999, Resolución $\mathrm{N}^{\circ}$ 294/99, y es el que se encuentra en vigencia actualmente.

Como mencioné, la institución surge por la iniciativa de un grupo de hombres que estaban interesados en llevar adelante una propuesta cultural para la ciudad. En los relatos

\footnotetext{
${ }^{8}$ Denominación utilizada por Ricardo Castro en la celebración del "Homenaje a los fundadores" en 1999. En: Programa de XXIII Abril Cultural Salteño. "Homenaje a los fundadores".
} 
aparece como una "necesidad" que Salta tiene, un "deseo" y "gusto" por las artes. Se proponen llevar a cabo un evento que durara un mes con diversas producciones artísticas porque era de lo que Salta estaba "hambrienta". ${ }^{9}$ Esos hombres hacen de su preferencia por determinadas actividades culturales (cine, teatro, música clásica, literatura) un proyecto común, extensivo a todos los habitantes de la ciudad. Sienten como propio una necesidad colectiva, haciendo de sus intereses el de todos los salteños.

Este proceso de construcción de imágenes colectivas parte de una referencia individual o bien de un grupo reducido de personas. Al respecto Norbert Elias sugiere que se trata de una interdependencia no sólo de imágenes sino de formas de experimentar el mundo. La "imagen de nosotros" y de "nuestro ideal" forman parte de la "autoimagen" y del "ideal de yo", tanto cuanto la "imagen e ideal de yo" de una persona singular que se refiere como "yo", implica al mismo tiempo una imagen personal como grupal (Elias, 2000: 41). Elias presenta una variedad de elementos a partir de los cuales se puede comprender la dinámica social, particularmente a través de las relaciones intersubjetivas y los mecanismos utilizados para hacer natural diferencias de las distribuciones de poder. Por otra parte ayuda a ver cómo distintas imágenes se consolidan y ejercen control social.

Iré mostrando que las personas que se aventuran a llevar a cabo un mes cultural pueden realizar una actividad con determinadas características porque disponen de ciertos atributos que le permite movilizar distintos recursos, muchos de ellos por las relaciones que establecen entre sí, pudiendo al mismo tiempo ampliar sus círculos de amigos. Una de ellas es Ramiro Peñalva que, como señalara su esposa Raquel, "tenía un perfil más institucional”. Tal vez ese perfil se deba a su participación como funcionario del Estado en años anteriores y, "conociendo cómo es la cosa", decide convocar a una asamblea, donde estuvieran presentes personas representando diversas instituciones del medio y todos aquellos individuos que pudieran estar interesados con la propuesta. La convocatoria fue publicada en el diario El Tribuno aunque también se telefonearon a las personas, siendo Raquel la encargada de ese asunto. ${ }^{10}$

En general las entidades que participaron de la asamblea fueron colegios de profesionales, asociaciones internacionales no gubernamentales que persiguen "fines

\footnotetext{
${ }^{9}$ Quien utiliza dicha expresión es Luciano Tanto.

${ }^{10}$ La descripción de esta asamblea se basa en los relatos de Raquel González de Peñalva, José Mario Carrer y de la narración hecha del libro "Pro Cultura Salta. XXX Abriles Culturales Salteños”, 2006.
} 
sociales", instituciones culturales y educacionales de diversa índole. También se convocaron a artistas (pintores, escultores, poetas, escritores, músicos, directores de coros, entre otros).

Entre esas personas estuvo Juan José Pautassi, artista plástico, paisajista, en representación del Club Kiwanis de Salta. El Club Kiwanis es una asociación civil creada en Estados Unidos en el año 1915, seguidamente se unió como miembro del Club Canadá. De él participan diferentes países del mundo y se orienta a trabajar con niños y adolescentes. Este Club en Salta apoyó diferentes tipos de actividades culturales y artísticas, sin necesariamente trabajar con problemáticas de niñez y adolescencia. Es una institución que al parecer no está más en Argentina ni en Salta. ${ }^{11}$

Esdras Gianella, como mencioné, fue un escultor y docente de la Escuela Provincial de Bellas Artes "Tomás Cabrera". A la asamblea fue como secretario del Club de Leones de Salta, lugar donde se realizaron ciclos de cine, exposiciones, se dieron conferencias, se hicieron reuniones sociales.

El Club de Leones, al igual que el Club Kiwanis o bien el Rotary Club, son formas de asociación que articulan redes locales, nacionales e internacionales, se asientan en diferentes territorios con el propósito de "solucionar problemas de salud, sociales y culturales de sus comunidades". 12 Este Club surge en los Estados Unidos entre 1915-1917, siendo su antecedente los "clubes de almuerzo", asociación que tenía como lema "recomienda mi negocio y recomendaré el tuyo", es decir que estuvo relacionado con la actividad económica originariamente.

Entre otros tipos de asociaciones culturales estuvieron presentes: Asociación Amigos de la Música que se reunía en la librería El Colegio. En su representación fue la señora María Fanny Rodríguez, escribana. También estuvo el señor Nicolás Jorge Sauma por el Coro Polifónico de Salta. Este coro se crea en 1948 por los sacerdotes católicos Francisco de Molina y Rafael Anduaga y un grupo de socios. Fue una de las primeras formaciones musicales en la provincia de repertorio clásico. ${ }^{13}$

\footnotetext{
${ }^{11}$ El Club Kiwanis tiene una página oficial en internet, donde se pueden ver sus propósitos y tipo de actividades que realizan. Las referencias sobre su participación en Salta fue dada por José Mario Carrer mediante intercambios de correos electrónicos.

12 Sugiero consultar la página web de esta institución, siendo la de Argentina: http://www.leonismoargentino.com.ar

${ }^{13}$ Sobre los procesos de formación de grupos musicales ver Navallo, 2007.
} 
También participó la Alianza Francesa y la Asociación Cultural ArgentinoBritánica, asociaciones que se dedican a difundir el idioma y la cultura francesa e inglesa respectivamente. Muchas veces esas instituciones promueven conferencias, exposiciones de artistas, conciertos de música, todo relacionado con los países referidos como también por el intercambio que pueda surgir con Argentina. En representación de dichas instituciones estuvieron Mario San Román, por la Alianza Francesa y Noemí Avellaneda y Elena Odriozola por la Asociación Cultural Argentino-Británica.

Participó también el Instituto Salteño de Cultura Hispánica. Desconocemos que tipo de actividad realizaron y/o realizan en Salta, aunque sí sabemos que es una organización creada por el gobierno español en 1946 aproximadamente, en el marco de un congreso. En ese contexto otros países "hispánicos" que asistieron apoyaron la creación del mismo. Éste se propone estudiar asuntos vinculados con la "hispanidad" en relación a una "historia común". ${ }^{14}$ En cada país la entidad mantiene personería jurídica propia y cuenta con sus propios recursos. En representación del instituto estuvo el señor Juan Antonio Urrestarazu Pizarro, abogado, presidente de dicha asociación y de LV9 Radio Salta.

Se encontró también Héctor Figueroa por el Ateneo Cultural El Tribuno. Éste fue creado por el diario El Tribuno, cuyo propietario por aquel entonces era el señor Roberto Romero que asumiera entre los años 1983-1989 la gobernación de la provincia. En el Ateneo Cultural se daban talleres de corte y confección, crochet, plomería, pintura, folklore (danza, música), electricidad, cursos de inglés, esgrima, entre otros. Éstos se realizaban en distintos barrios de la ciudad, generalmente en los centros vecinales. Con el tiempo el "Ateneo Cultural" devendrá "Fundación Roberto Romero" ofreciendo más o menos el mismo tipo de actividades, aunque siendo fundación contarán con un edificio propio en el centro de la ciudad de Salta.

Entre los grupos de profesionales que asistieron a esa reunión estuvieron los representantes de: Cámara de Comercio e Industria, Cámara de Turismo, Cámara de Librerías y Papelerías, Asociación Salteña de Agencias de Publicidades, Colegio de Abogados, Colegio de Escribanos, Colegio de Profesionales de Ciencias Económicas, Círculo Médico de Salta, Asociación de Odontología.

\footnotetext{
${ }^{14} \mathrm{Al}$ respecto consultamos las páginas: http://www.culturahispanicacba.com.ar/
} 
Por la Cámara de Industria y Comercio estuvo José Mario Carrer, oftalmólogo y dueño de una óptica; ${ }^{15}$ Pedro Néstor Fernández por la Asociación Salteña de Agencias de Publicidad; Benito Crivelli por la Cámara de Librerías y Papelerías, sobre quien ya hicimos referencia; Mario D'Jallad por el Colegio de Abogados; Pascual Zarzoso por la Cámara de Turismo; Nora L. Morales de Colina por el Círculo Médico; Luis J. Brandán por la Asociación de Odontología; Fernando Magadán y Haydée Alvarengo de Magadán por el Consejo Profesional de Ciencias Económicas.

Después asistieron personas como Arturo D. Boteri, fotógrafo y profesor de filosofía y psicología de los colegios secundarios Belgrano y Polivalente de Artes; Norma M. Campos; Ramiro A. Peñalva y Raquel M. González de Peñalva; Julio Moreno; Jorge Hugo Román, artista plástico; Julio Ovejero Paz, abogado, en representación de la Universidad Nacional de Salta y José Juan Botelli, músico y poeta, quien asumiera por algunos meses la Dirección General de Cultura, durante 1976.

En esa asamblea se crea Pro Cultura Salta, escogiéndose la figura legal de "asociación civil sin fines de lucro" que tuvo como principal objetivo realizar un mes cultural al que denominaron Abril Cultural Salteño. De ella surge la primera comisión directiva, teniendo la siguiente configuración:

\footnotetext{
${ }^{15}$ José Mario Carrer (4/12/1937). Crítico musical, perteneciente a la Academia de Críticos de Música de la Argentina, realiza esta actividad en El Tribuno desde 1986 y en www.mundoclasico.com desde 1999. Autor del libro "La música que yo viví". Presidente de la Cámara de Comercio e Industria de Salta. Presidente de la Cámara de ópticas de Salta. Oftalmólogo, profesión que ejerce. Director General de Cultura (1991-1995), durante la gobernación democrática del General de Navío el señor Augusto Ulloa. Cofundador del Abril Cultural Salteño y miembro de Pro Cultura Salta. Cofundador y presidente del Mozarteum Argentino filial Salta. Cofundador de la Fundación Banco del Noroeste (hoy Fundación Salta). Cofundador y vicepresidente de la Fundación del Banco Provincial de Salta. Vicepresidente de la Unión de Entidades Comerciales Argentinas. Vicepresidente de la Cámara Argentina de Comercio. Vicepresidente de la Ferinoa (Feria Internacional del Noroeste Argentino). Vicepresidente del Instituto Provincial de Seguros.

Prefiere presentarse como "un hombre desesperado por el desarrollo cultural de la gente de mi provincia". Modo de presentación que surgió durante un diálogo que mantuvimos y en el cual pregunté cómo le gustaría ser presentado, además de todas las ocupaciones que desempeñó.

Algunos de esos datos fueron extraídos de "Periodismo y literatura. El campo cultural salteño del '60 al 2000". Libro publicado por la Editorial de la Universidad Nacional de Salta en el año 2007, basado en un proyecto de investigación colectivo dirigido por Susana Rodriguez y co-dirigido por Elisa Moyano.
} 


\section{Cuadro $\mathrm{N}^{\circ} 1$}

\begin{tabular}{|l|l|}
\hline Directorio de Pro Cultura Salta & Integrantes \\
\hline Presidente & Ricardo Castro \\
\hline Vicepresidente & Ramiro Peñalva \\
\hline Secretario & Esdras Gianella \\
\hline Tesorero & Fernando Magadán \\
\hline Vocales & $\begin{array}{l}\text { Benito Crivelli } \\
\text { José Mario Carrer } \\
\text { María Fanny Rodriguez }\end{array}$ \\
\hline $\begin{array}{l}\text { Órgano de Fiscalización } \\
\text { Sitular }\end{array}$ & $\begin{array}{l}\text { Guillermo Juan Schwarz } \\
\text { Nora L. M. de Colina }\end{array}$ \\
\hline
\end{tabular}

La asamblea da cuenta de las relaciones personales que los individuos mantenían entre sí, como mostré a partir de las charlas de café, es decir un grupo reducido de personas amplió y citó a su círculo de amigos. Tal es así que la señora Raquel Peñalva llama personalmente a algunas personas, además de usar los medios de comunicación para la convocatoria.

En el libro "XXX Abriles Culturales Salteños" la narración de la asamblea no describe los vínculos que tenían los individuos que asistieron. Si bien se nombra a cada uno, son presentados en relación a las instituciones. Aunque, como Raquel supo comentarme, se buscaba que las personas que asistieran formaran parte de alguna entidad, sea colegios de profesionales, asociaciones culturales, instituciones educativas, para conseguir los recursos económicos que el Abril Cultural demandaría.

Ese primer directorio se basa en ese estrecho núcleo de conocidos, con quienes se mantiene determinada afinidad, elemento que permite las alianzas entre las personas y define una amistad, tal como Pitt-Rivers (1971) señaló. Ricardo Castro era amigo de Esdras Gianella, Ramiro Peñalva, Benito Crivelli. Benito a su vez conocía a María Fanny Rodriguez, por su participación en Amigos de la Música, encuentro que se realizaban en su librería y Fanny también era amiga de José Mario Carrer, por la afinidad que compartían por la música clásica. Fernando Magadán se entusiasma con la idea y se queda en Pro 
Cultura Salta hasta fines de los años noventa, algo semejante sucede con Nora L. Morales de Colina, quien participó muchos años en el directorio.

Si bien algunos mantuvieron una relación más estrecha y afectiva, otros la fueron consolidando en la propia institución. Es importante marcar que las instituciones que colaboraron durante años se caracterizan por ser entidades no sólo con propósitos sociales sino que su actuación excede tanto las fronteras provinciales como nacionales. Los fondos de dichas entidades son gestionados y distribuidos en esos niveles de circulación.

Destaco esto porque autores como George Yúdice (2002) apuntan a este fenómeno social atribuyéndole como una característica de la globalización y de políticas neoliberales. Este autor está concibiendo otro tipo de organizaciones que ponen en movimiento capitales financieros para la producción cultural internacional: Banco Mundial, Banco Interamericano de Desarrollo, Bancos Multilaterales, organizaciones civiles y no gubernamentales.

Sin embargo, esa movilidad de recursos económicos y también sociales estuvo presente en décadas anteriores a las evocadas por la globalización, en general referida durante los noventas y en adelante. La dinámica de movilización de recursos a través de diversas fronteras puede ser localizada en una asociación como "Dante Aghilieri", promotora de la cultura y del idioma italiano, la cual traía músicos de ese país para que efectuaran sus repertorios en distintas localidades argentinas, es decir que se trata de un conjunto de instituciones con otras características que perseguían fines sociales para el "desarrollo humano", al mismo tiempo que funcionaban como espacios de socialización.

Todos estos elementos son apagados en el acta fundacional de 1979 por su cualidad como documento jurídico. En él se mencionan las personas, su estado civil, su dirección, su documento nacional de identidad, su domicilio, y allí no aparecen los vínculos de proximidad entre los sujetos a no ser que estuvieran casados. En el libro de los "XXX Abriles Culturales Salteños" cuando su escritora Carmen Martorell, también miembro del directorio, destaca la "idea extraordinaria" de un grupo de personas, la "mística y permanencia" de la institución, la "benevolencia" y el "compromiso" de los sujetos involucrados, apela a un conjunto de elementos afectivos para recordarlos con "cariño" aunque no necesariamente para mencionar las afinidades entre los miembros de la asociación. 
A través de esas fuentes documentales y de las charlas que mantuve con algunas de las personas que integraron el directorio de Pro Cultura pude establecer los vínculos de proximidad entre los individuos y cómo las relaciones entre ellos construidas permitía la articulación de diversas entidades civiles.

\section{El acta de fundación}

El "acta de fundación, aprobación de estatutos y elección de presidente y miembros del directorio de la asociación civil Pro Cultura Salta" que analizaré data del 14 de noviembre de 1979.

En ella se encuentran los nombres de las distintas personas que participaron en "asamblea constituyente". En el acta se establece un "orden del día" de los asuntos a tratarse: a) fundación de la entidad; b) aprobación de los estatutos sociales; c) elección de las autoridades y d) designación de dos personas para tramitar la obtención de la personería jurídica de la asociación.

La asamblea que produce su acta de fundación no coincide con la asamblea recientemente descripta y, como se verá, su directorio también será diferente. Es decir que se trata de dos momentos en la institución aunque esta segunda asamblea efectiviza la creación de Pro Cultura Salta.

Entre los participantes que se mantienen en ambas son: Benito Crivelli; Fernando Magadán; Haydée Alvarengo de Magadán; Ramiro Peñalva; Raquel González de Peñalva; José Mario Carrer; Julio Ovejero Paz; Mario Ricardo D’Jallad. Quienes asisten para esta ocasión y que no estuvieron en la anterior son: Jorge Oscar López; Manuel Eudaldo Cabral; Mirta Susana D’Agata de Cabral; Blanca Tapia Gómez, Luis Eduardo López; Elsa Salfity; Ernesto Jacobo Lachs; José Alberto Melendez e Hilda Beatriz Bitar de Melendez.

El acta da cuenta de la realización del primer orden del día, la fundación de "Pro Cultura Salta". Seguidamente se "reconoce su origen en el ente del mismo nombre que funciona de hecho desde el 17 de diciembre de 1976 y que, aunando el esfuerzo de toda Salta, organizó y realizó tres ciclos del ‘Abril Cultural Salteño' en los años 1977, 1978 y 1979".

"Después de amplias deliberaciones" se resuelven los estatutos y se reelige el directorio, quedando la siguiente configuración: 
Cuadro $\mathrm{N}^{\circ}: 2$

\begin{tabular}{|l|l|}
\hline Directorio de Pro Cultura Salta & Integrantes \\
\hline Presidente & Benito Crivelli \\
\hline Vicepresidente & Fernando Magadán \\
\hline Secretario & Luis Eduardo López \\
\hline Tesorera & Blanca Tapia de López \\
\hline Vocales & $\begin{array}{l}\text { Jorge Oscar López } \\
\text { Manuel Eudaldo Cabral } \\
\text { Mario Ricardo D'Jallad }\end{array}$ \\
\hline Vocales Suplentes & $\begin{array}{l}\text { Ernesto Jacobo Lachs } \\
\text { Elsa Salfity } \\
\text { Mirta Susana D'Agata de Cabral }\end{array}$ \\
\hline $\begin{array}{l}\text { Órgano de Fiscalización } \\
\text { Titular } \\
\text { Suplente }\end{array}$ & $\begin{array}{l}\text { Contadora Pública Nacional Hilda Beatriz } \\
\text { Bitar de Cabral } \\
\text { C.P.N. Haydée Alvarengo de Magadán }\end{array}$ \\
\hline
\end{tabular}

Dejan de participar del directorio los señores Ricardo Castro, José Mario Carrer y Ramiro Peñalva. Éste último ya había asumido el cargo de Director- Interventor de la Dirección General de Cultura de la Provincia, a partir del día 26 de julio de 1977, decreto provincial n 2477 .

José Mario Carrer comenta que su alejamiento de la institución se debió a la transformación de los criterios en torno a cómo conseguir que los diferentes grupos fueran a Salta a participar del Abril Cultural Salteño. En los primeros años se buscó hablar directamente con los artistas, "comprometerlos con la idea", evitar negociaciones con los representantes y de esa manera reducir los gastos de producción. Eso significó que las personas que constituían el directorio se dedicaran exclusivamente a eso, tener disponibilidad horaria y económica para viajar a Buenos Aires o Tucumán y encontrarse personalmente con los artistas y de esa forma hablarles del Abril Cultural. Con los años eso se fue modificando y las personas que fueron ingresando al directorio no compartían el mismo principio, ante esa situación José Mario Carrer decide desvincularse de Pro Cultura. Se puede deducir que Ricardo Castro probablemente se alejó por divergencias semejantes 
aunque él no dejó de incorporar, como parte de la programación de los Abriles Culturales, el ciclo de cine Arte, que durante algunos años se llamó ciclo de cine Maldito.

Una vez establecido el nuevo directorio se designaron las personas encargadas de tramitar la personería jurídica de la entidad, ellos fueron Mario Ricardo D’Jallad y Manuel Eudaldo Cabral, quienes a su vez tuvieron la libertad de "hacer modificaciones en el estatuto” en caso que así lo exigiera la Inspección General de Personas Jurídicas.

\section{El estatuto social}

El estatuto social que rige la asociación civil mantiene un lenguaje administrativo, ${ }^{\mathbf{1 6}}$ en el cual se detallan los objetivos que tiene la entidad, las acciones que se propone desarrollar, las funciones que le caben a cada uno de los miembros del directorio, la frecuencia de sus encuentros, la calidad de las convocatorias (asambleas ordinarias o extraordinarias), el órgano encargado de administrar los recursos y rendir cuentas al Estado, las sanciones impartidas a los miembros ante cualquier incumplimiento de sus tareas, la dinámica establecida con los socios y la participación que éstos pueden asumir por el tipo de "sociedad" que establezca con la institución. Este lenguaje administrativo que aparenta neutralidad y se propone fines definidos convive con otro complemente emotivo, desinteresado, humanista porque apunta al mejoramiento de la vida de los seres humanos mediante la promoción artística.

La asociación para poder actuar y conseguir sus propósitos requiere de la formalización de sus intereses, aunque éstos pretendan ser ajenos a la política. Sin embargo, ese proceso de institucionalización da lugar a la formación misma del Estado, éste se produce en tanto y en cuanto establece la demarcación de sus funciones, delega en otras entidades ciertas labores, mientras se encarga de controlar y fiscalizar cómo las actividades de las diversas instituciones que no lo constituyen llevan a cabo sus tareas. El Estado crea

\footnotetext{
${ }^{16}$ La relación con el lenguaje quiero establecerla a partir de las sugerencias propuestas por Cris Shore y Susan Wright (1997). Los autores señalan que una característica de las policies es el lenguaje en ella utilizado, generalmente "neutral y objetivo" que condice con una lógica de la legalidad racional. Sin embargo, enmascara los procesos de normalización y sujeción que producen en los individuos. Por eso éste resulta, por un lado, una "clave" para entender la arquitectura de las relaciones de poder, en tanto que movilizan distintos tipos de metáforas, producen efectos, crean imágenes... Esas metáforas se conjugan con otras, como por ejemplo "nación", "país", "provincia”, “comunidad”, "pueblo", “democracia”, "región”. Por otro, se refiere con el carácter persuasivo de los discursos, que merecen ser considerados como "políticas de las prácticas discursiva”. Finalmente se trata de ver ¿Cuáles son las luchas suscitadas a través de "palabras claves”? (Shore \& Wright, 1997: 20).
} 
la separación de sí con la sociedad y en esa diferenciación caben las asociaciones civiles. Ese proceso es lo que Mitchell (1999) denominó como “efecto de Estado”, preguntándose ¿cómo se establecen los límites entre Estado y sociedad? ¿Con qué técnicas? ¿Qué marca el exterior del Estado?

Los límites son tenues, las líneas no son ilusorias, se establece esa separación mediante códigos civiles, comerciales, jurídicos en general, mirar su proceso de formación constituye nuestra labor. Por eso encuentro que atender a las relaciones personales configurándose en redes sociales permiten indagar sobre esas cuestiones.

Varios de los miembros de Pro Cultura Salta ya entablaban esos vínculos, el caso más sobresaliente es Ramiro Peñalva, que a poco tiempo de formar parte del directorio asume rápidamente el cargo de Director General de Cultura, como ya señalé. Otros como Elsa Salfity, segunda vocal del directorio entre 1979-1983, sería al mismo tiempo directora de la Escuela Provincial de Bellas Artes durante el período 1976-1979. Parte de su gestión en esa escuela consistió la remodelación edilicia primero y luego la tramitación de un nuevo establecimiento.

Las relaciones interpersonales conforman "estructuras intersticiales” (Wolf, 1966), o bien como señala Bezerra ellas "atraviesan, coexisten y desempeñan tareas en el contexto del cuadro institucionalizado" (1995: 38). Ese cuadro institucionalizado puede ser tanto la propia asociación Pro Cultura Salta como la administración pública provincial. Los intersticios no refieren sólo a los lugares donde se hacen las amistades sino al tipo de vínculo que estructuran las prácticas sociales en general y las funciones públicas en particular.

Volviendo al estatuto social conviene destacar que tuvo como finalidad específica "propender a la elevación y desarrollo del nivel cultural de la población de la Provincia", mediante diferentes actividades artísticas, entre ellas: el cine, el teatro, la música, ${ }^{17}$ las artes plásticas (pintura, grabado, escultura, xilografía, etc., es decir por medio de diferentes técnicas), la literatura, la fotografía, y “otras disciplinas”, entendiendo por otras disciplinas, asociación que establezco a partir del análisis de los programas llevados a cabo, la filosofía,

\footnotetext{
${ }^{17}$ Se habla de la música en términos genéricos, mayoritariamente a lo que se entiende coloquialmente por "música clásica", en menor medida el folklore, el rock, el jazz. No se incorporan nunca géneros musicales como la cumbia o el cuarteto, siendo éstos, principalmente la cumbia, para el caso de Salta y el norte argentino en general, ampliamente difundida y escuchada por los sectores populares.
} 
la antropología, la arqueología, la historia. De alguna manera se tratan de acciones vinculadas con la educación en general, en muchos casos refieren a los vínculos que éstas puedan crear con el arte (la negrita me pertenece). ${ }^{18}$

Se previó realizar

salones de pintura, escultura, grabado y dibujo; exposiciones individuales y colectivas de arte; salones de fotografía; concursos literarios; presentación de espectáculos teatrales y cinematográficos; publicación de conferencias, cursillos, seminarios y mesas redondas aludidas y de las obras premiadas en los concursos literarios; muestras de documentación histórica; audiovisuales sobre distintos temas; muestras de artesanías, etc.; todo ello dentro de la más elevada jerarquía y la mayor calidad posible, bajo la denominación de "Abril Cultural Salteño" (El destacado me pertenece). ${ }^{19}$

Por otra parte se tuvo en cuenta que existieran "premios adquisiciones", con el objetivo de contribuir al incremento del "patrimonio provincial". Con los años se verá que las "empresas patrocinadoras" otorgarán un premio de esa categoría, por ejemplo "premio adquisición Cerveza Salta", aunque la obra "adquirida" no queda en manos de la empresa o institución promotora sino que ésta a su vez la "dona" a la provincia. ${ }^{20}$

El estatuto no define explícitamente qué es arte o cultura, aunque con la enunciación de las disciplinas promovidas establece cuáles son consideradas como tal. Se subraya solamente que éstas sean de la "más elevada jerarquía y [de] la mayor calidad". Ese conjunto de actividades, acompañadas de prácticas relativas a ellas (cursos, seminarios, conciertos, exposiciones, proyecciones, etc.) producirán indirectamente una noción de cultura, referida fundamentalmente a esas disciplinas artísticas. Por lo tanto emplearán arte y cultura como términos intercambiables. Y, cuando se hable de prácticas culturales referirá también a esas disciplinas.

En el estatuto se explicita minuciosamente cómo pretende Pro Cultura llevar a cabo su proyecto, el tipo de acciones que desarrollará, con qué instituciones se asociará. Esclarece que sin el apoyo de otras organizaciones sería imposible cumplir su misión.

Otro de los objetivos de la asociación se vincula con la difusión del programa del Abril Cultural Salteño tanto en la ciudad de Salta como en diversas localidades del interior

\footnotetext{
${ }^{18}$ Se trata de los artículos $2^{\circ}$ y $3^{\circ}$ del estatuto social.

${ }^{19}$ Artículos $2^{\circ}$ y $3^{\circ}$ del estatuto social.

${ }^{20} \mathrm{El}$ funcionamiento de las adquisiciones por parte de las empresas es complejo. En general esos galardones otorgan como premio una determinada cantidad de dinero a los artistas, a su vez éstas donan esas obras, probablemente por la liberación de un porcentaje del impuesto a las ganancias.
} 
de la provincia, algo que se realiza desde el primer Abril Cultural. Esa propuesta es señalada como una "irradiación hacia el interior", siendo el centro la ciudad de Salta.

La propuesta de Pro Cultura Salta puede ser concebida como una policy, en tanto y en cuanto se trata de "planes, acciones y tecnologías de gobierno formuladas no sólo desde organizaciones administrativas de los Estados Nacionales" (Souza Lima e Macedo e Castro, 2008: 369). Entendiéndose por gobierno a aquello que influencia las normas y conductas de las personas en un orden social específico.

Este tipo de política, que puede ser llamada de gubernamental, aunque lo gubernamental muchas veces puede asociarse con la administración pública y el caso de Pro Cultura Salta transita el "Estado" y la "sociedad", codifican explícita o implícitamente normas y valores sociales, articulando principios de organización social, constituyen modelos de sociedad y una guía de acción (Shore y Wright, 1997: 6).

La acción que se propone poner en marcha la institución se vincula con el área artística, fomentando el "cultivo" del espíritu de los salteños. El proyecto de la asociación está avocado a dirigir sus acciones en relación al arte y la cultura, por ello quiere involucrar a diversas instituciones: escuelas, universidades, medios de comunicación, diferentes "organismos culturales, turísticos, deportivos", empresas, industrias, colegios de profesionales.

En lo que atañe a las entidades educativas (privadas o públicas) se propone colaborar, a través de los Abriles Culturales, a "revisar los programas de formación plástica y musical". Mientras los estudiantes sean "alentados a la concurrencia", "guiados" en las exposiciones, es decir que se formen.

$\mathrm{Si}$ se mantiene la idea acerca de las policies en tanto que ellas son formas de gobierno, producen sujetos sociales y morales, al tiempo constituyen modelos de sociedad, en esos términos se podría afirmar que efectivamente Pro Cultura lleva a cabo una política gubernamental, una política cultural.

\section{Las dimensiones (anti)políticas de la cultura}

Norbert Elias (1997) en "Uma digressão sobre o nacionalismo" se propone discutir en torno a la formación de nacionalismos tomando como punto de partida los sentidos de los términos de civilización y cultura y la asociación de ellos con un tipo de práctica 
histórica. Para dar cuenta de ese proceso analiza un grupo de intelectuales alemanes de clase media del siglo XVIII que utilizaba el término cultura para expresar su auto imagen y sus ideales. En ellos cultura era vista para dar cuenta del desarrollo general de la humanidad.

Entre las preguntas levantadas por el autor se destaca cómo civilización y cultura en el siglo XVIII se referían a procesos sociales, mientras que en el siglo XX alude a términos estáticos. La definición etimológica de cultura describe al proceso de transformación de la naturaleza por los seres humanos mediante un proceso de cultivo, significado actualizado a partir del renacimiento. Elias llamará la atención sobre la pérdida del carácter procesual del término en el siglo XX, tornándose más bien un estado de cosas.

Estos elementos son los que contribuirán con posterioridad al desarrollo del nacionalismo, porque al reificarse la noción de cultura dará lugar a la emergencia de características sustanciales como definidoras de una colectividad asentada en territorios delimitados.

Los intelectuales del siglo XVIII emplearon el término alemán de kultur (cultura) para formular una historia de la cultura distanciada una historia de la política (enfocada en las proezas de los príncipes y las cortes de los Estados absolutista) y para borrar toda connotación política en esa formulación, siendo percibida la cultura por excelencia como antipolítica y humanista, centrada en el desarrollo del ser humano.

Tanto la dimensión a-política de cultura como un proceso de cultivo del espíritu aparecerá entre las acciones que se propone Pro Cultura Salta, el objetivo primordial, como señalé reiteradas veces, es precisamente la "elevación del nivel cultural de la población de la provincia". Los actores de este proyecto utilizan la cultura para legitimar sus posiciones como establishment, mientras promueven el cultivo del espíritu de los salteños.

Es en ese proceso de "elevar el nivel cultural de la población” que se configura una forma de experimentar lo salteño y de devenir salteño. El arte y la cultura serán los medios por los cuales las personas se tornan sujetos dignos, individuos cultos y civilizados.

Los Abriles Culturales Salteños a lo largo de sus años sufren muchas modificaciones, aunque existen algunos elementos que le dan continuidad y éstos se relacionan con el interés de su directorio de afirmar aspectos que dan cuenta de lo salteño. Lo salteño referirá muchas veces a la naturaleza del lugar, a la tierra que es "amplia y 
generosa" porque permite que la cultura se desarrolle allí. Sin embargo, en ese brotar de lo salteño de una tierra generosa que es "por naturaleza" "rica en cultura", se señala el esfuerzo realizado por las personas que conforman el directorio de Pro Cultura para que "un año más" el Abril Cultural se concretice. No existe cultura sin el trabajo laborioso para que de la tierra emerjan grandes cosas.

Los promotores del Abril Cultural Salteño hacen todo "voluntariamente", en esa afirmación manifiestan su desinterés, no persiguen ganancias de ningún tipo por la labor emprendida; llevan a cabo los Abriles Culturales sólo por el amor que las personas tienen por el desarrollo cultural y la preocupación de "elevar" el nivel cultural de las personas. Se trata de un amor por al arte y la cultura que estos sujetos comparten entre sí y extienden su deseo tornándolo el de toda la Provincia.

Por otra parte cuando se habla de los Abriles Culturales se asienta que en realidad lo éstos hicieron "en todos esos años" fue crear una "imagen de Salta". Se "sacó" y "presentó" a Salta y a los artistas locales, se les "dio presencia". ${ }^{21}$ Salta se construye para sí dentro de sus fronteras políticas al tiempo que se constituye y resignifica como provincia en una comunidad política nacional. Comunidad que se consolida, para usar los términos de Max Weber, por un conjunto de lazos sociales y afectivos o bien por los procesos de comunización en la medida que se fortalece un sentimiento común (2005: 317).

Elias (1997) alertó sobre la constitución de códigos morales. Uno de los valores declarado en el acta fundacional es la afirmación de una "solvencia moral intachable" como característica inherente a las personas que quieran integrar el directorio de Pro Cultura Salta. Paradójicamente es un valor que forja valor, en la medida que su formulación como elemento constitutivo de un estatuto procede de un valor moral anterior a la colocación como mandato y, como tal, debe ser obedecida.

Sobre esos valores y códigos la asociación civil produce su legitimidad permitiéndole así encarnar el objetivo principal de "elevar el nivel cultural” de las personas mediante la realización de actividades de "la más alta jerarquía y calidad".

Asimismo se nota que sus finalidades se orientan a presentar espectáculos de jerarquía que muestren el "progreso" de la ciudad y el interés de formar públicos a través de exhibiciones, cursillos, seminarios, conferencias, talleres. Pro Cultura Salta actúa

\footnotetext{
${ }^{21}$ Afirmación realizada por la señora Carmen Martorell.
} 
conjuntamente con "organismos oficiales y privados" para llevar a cabo sus objetivos. De esta manera, se podría decir entonces que el proyecto de la entidad tiende a ser totalizador, de tal forma que abarca todos los ámbitos entendidos como culturales y todas las actividades que en esa denominación quepan.

Este proceso social particular me conduce a señalar que la cultura no es para nada un campo de acción desinteresado, al contrario moviliza un conjunto de recursos sociales, económicos y propiamente políticos que producen pugnas por controlarlo. Considero que mediante ese interés desinteresado, en el sentido de que no existen los dones desinteresados apuntados por Pierre Bourdieu ${ }^{22}$ y parafraseándolo, se generan formas de dominación, obediencia y gobierno.

\section{Recapitulando}

Analizando Pro Cultura Salta pude notar que los sujetos que formaron y forman la institución conciben su trabajo como una práctica desinteresada, se hace lo que se hace por el gusto, el amor y la pasión que se tiene y siente por el arte. En este sentido esas acciones sociales son percibidas como a-políticas. Sin embargo, viendo cómo surge la institución y el tipo de relaciones que las personas mantienen entre sí, se nota el carácter ficcional de esa enunciación. Por el contrario, las personas que idearon Pro Cultura Salta como los Abriles Culturales Salteños se encuentran posicionadas en determinados lugares no sólo estratégicos sino vinculados a la administración pública y a diversas instituciones civiles que les permiten activar diversos tipos de recursos. La referencia a la presencia de los miembros del directorio como funcionarios del Estado no quiere simplemente marcar esa relación y tránsito, sino que busca mostrar cómo la posibilidad de estar en diversas entidades produce que las actividades de ellas se fundan y que se produzca el efecto de Estado del cual nos habla Mitchell.

Pro Cultura Salta se pone al servicio, se encarga de gestionar esa tarea, intermediar entre las empresas, el gobierno y conseguir recursos para ofrecer los Abriles Culturales a la

\footnotetext{
${ }^{22}$ Pierre Bourdieu (1996) señala que el "desinterés" es uno de elementos que constituyen la lógica de los intercambios de los bienes simbólicos. Dirá que existe un self-deception colectivo en la economía de bienes simbólicos, economía antieconómica, que se fundamenta en la denegación (verneinung) del interés y del cálculo o el trabajo colectivo de manutención. Cuando se efectúa un "don generoso", sin esperar una retribución, se está actuando de acuerdo a la lógica del intercambio de los bienes simbólicos, que consiste en "ignorar" la regla.
} 
población. Practica una política gubernamental, ritma con las transformaciones del Estado provincial y articula entre diversos sectores de la administración pública. Porque construye sus relaciones por vínculos de proximidad, interpersonales e interdependientes y gracias a que diversos miembros cumplen funciones fuera de la asociación (Cámara de Comercio, relaciones personales con el dueño de los medios de comunicación, Director de Cultura, entre otros) consigue llevar adelante ese proyecto.

El Abril Cultural realiza una actividad pedagógica en la medida que presenta al tiempo que educa a los espectadores en torno a qué vale o cuenta como cultura y como obra artística. Durante un poco más de treinta años sin interrupción en la puesta en marcha de los Abriles Culturales cabe destacar que no siempre tuvo la misma preeminencia ni presencia en los diversos períodos de gobierno. Por lo tanto se destacan discontinuidades y contrapuntos entre los discursos pronunciados por los miembros de Pro Cultura y las acciones llevadas a cabo. Sin embargo, puede señalarse una creciente apropiación de los Abriles Culturales por parte del Estado provincial, es decir que la ejecución de éstos es llevada a cabo por diversas instituciones y administraciones del gobierno provincial, quedando a Pro Cultura la organización y pensar sobre qué se presentará y cómo se lo llevará adelante. En este sentido, la asociación fue consolidándose a través de los años como un órgano de pensamiento del Estado (Durkheim: 1974), y de esta manera afirmo que el mes cultural deviene en una política gubernamental.

Salta fantasea "cultura" y se imagina a sí misma como cultura, los miembros de la asociación se embarcan a tornar realidad ese proyecto, hacen de su deseo el deseo de todos, se adjudican una misión social y política. La cultura legítima que imaginan es aquella de los valores universales y las artes europeas. En ese sentido aquello que comienza como charlas de café deviene en un proyecto de civilización que busca transformar al individuo, a través del cultivo de sí, siendo el arte el modo de espiritualizarse.

\section{Referências}

BEZERRA, Marcos Otavio. Corrupção. Um estudo sobre o poder público e relações pessoais no Brasil. Rio de Janeiro: Relume Dumara, ANPOCS, 1995.

BOURDIEU, Pierre. "Marginália. Algumas Notas Adicionais sobre o Dom". In: Mana, v.2, $\mathrm{n}^{\circ}$ 2. Rio de Janeiro: PPGAS - Museu Nacional - UFRJ,1996. p. 7-20.

DURKHEIM, Emile. Lecciones de Sociología. Buenos Aires: La Pleyade, 1974. p. 87-158. 
ELIAS, Norbert. Os Alemães. A luta pelo poder e a evoluçao do habitus nos séculos XIX e $X X$. Rio de Janerio: Jorge Zahar Editor, 1997. p. 119-158.

ELIAS, Norbert e SCOTSON, John. Os estabelecidos e os outsiders: Sociologia das relações de poder a partir de uma pequena comunidade. Rio de Janeiro: Zahar, 2000. p. 19-50.

IBAÑEZ, Marta Ofelia; GUZMÁN, Raquel; MOYANO, Elisa y RODRIGUEZ, Susana. Periodismo y literatura. El campo cultural salteño del '60 al 2000. Salta: EDUNSa, 2007. p. $17-41$.

LIMA, Antonio C. de Souza; CASTRO, J.P.M.E. "Política(s) Pública(s)". In: PINHO, Osmundo \& SANSONE, Livio (Eds.). (Org.). Raça: Perspectivas Antropológicas. Salvador: EDUFBA, 2008. p. 141-193.

LISÉ, Gloria. Con los pies en el escenario. Trayectoria del Grupo Arte Dramático y su Director Salo Lisé. Salta: Artes Graficas Crivelli, 2003.

MITCHELL, Timothy. "State, Economy, and the State Effect". In: STEIMENTZ, George (Ed.). State/culture: state formation after de cultural turn. Cornell: Cornell University Press, 1999. p.77-97.

NAVAllO, Laura Belén. Tocando Cultura. Políticas y poéticas del término "cultura" a partir de un análisis de los procesos sociales de creación de la Orquesta Sinfónica de Salta. (Licenciatura en Antropologia) -Escuela de Antropologia, Universidad Nacional de Salta, 2007.

NAVALlO, Laura Belén. Fazer Cultura. Arte e política cultural em Salta, Argentina. (Disertación de Maestría en Antropología Social) - Programa de Pós Graduação em Antropologia Social. Museu Nacional. Universidade Federal de Rio de Janeiro, 2010.

PITT-RIVERS, Julian. "Friends and authority". In: PITT-RIVERS, Julian. The People of the Sierra. London: The University Chicago Press, 1971. p. 137-160.

PROGRAMA DE XXIII ABRIL CULTURAL SALTEÑO - Homenaje a los fundadores, 1999.

PRO CULTURA SALTA. XXX Abriles Culturales Salteños. Buenos Aires: Edge_Pre Media, 2006.

RESOLUCIÓN N 558-D, RESOLUCIÓN N² 294/99. Ministerio de Gobierno, Justicia y Educación de la Provincia.

SHORE, Chris \& WRIGHT, Susan. "Policy: a new field of anthropology". In: SHORE, Chris \& WRIGHT, Susan. (Eds.). Anthropology of policy. Critical perspective on governancce and power. London and New York: Routledge, 1997. P. 3-39.

WEBER, Max. Economía y sociedad. Mexico: Fondo de Cultura Economica, 2005. p.5-45; 315-327.

WOLF, Eric. "Kinship, Friendship, and Patron Client Relations in Complex Societies". In: BANTON, Michael (org). The social anthropology of complex societies. Londres: Tavivistock Publication Limited, 1966. p. 1-22.

YUDICE, George. El recurso de la cultura. Usos de la cultura en la era global. Barcelona: Ed. Gedisa, 2002. p. 13-105. 